\title{
SPERM PENETRATION IN VITRO OF MOUSE OOCYTES AT VARIOUS TIMES DURING MATURATION
}

\author{
T. IWAMATSU* AND M. C. CHANG \\ Worcester Foundation for Experimental Biology, \\ Shrewsbury, Massachusetts 01545, U.S.A.
}

(Received 4th October 1971, accepted 24th Fanuary 1972)

\begin{abstract}
Summary. Mouse ovarian oocytes at various stages of maturation were collected and inseminated with preincubated (capacitated) spermatozoa. Within $1 \mathrm{hr}$ of insemination, sperm penetration into the perivitelline space was observed in oocytes at any stage of maturation. The proportion of oocytes with spermatozoa in the perivitelline space and in the vitellus $1 \mathrm{hr}$ after insemination increased as the nuclear maturation of oocytes advanced to Metaphase I-Telophase I. In the oocytes penetrated earlier than Metaphase I, the swollen sperm head changed to condensed chromatin and, in some, the chromatin changed into a spindle-like form. The proportion of oocytes with well-formed pronuclei increased markedly when oocytes were inseminated $10 \mathrm{hr}$ after the injection of HCG at the stage of Metaphase I-Telophase I. It appears that the reactivity of oocytes to spermatozoa occurred gradually after the breakdown of the germinal vesicle and their fertilizability was acquired just before, or at the time of, completion of the first maturation division.
\end{abstract}

\section{INTRODUGTION}

In mice, the eggs are fertilized soon after ovulation at the metaphase of the second maturation stage, but it is not known whether the oocytes can be penetrated at an earlier stage of maturation. The nuclear maturation of mouse ovarian oocytes in vitro (Edwards, 1965; Donahue, 1968), the successful fertilization of recently ovulated mouse eggs in vitro (Whittingham, 1968; Iwamatsu \& Chang, 1969, 1970; Mukherjee \& Cohen, 1970), the maturation of mouse oocytes in vitro and subsequent fertilization in vitro (Cross \& Brinster, 1970), and the fertilization in vitro of ovarian oocytes just before ovulation (Iwamatsu \& Chang, 1971) have been reported. Since the capacitation of hamster (Yanagimachi, 1969) or mouse (Iwamatsu \& Chang, 1969, 1970) spermatozoa can be achieved in vitro by treatment with heated bovine follicular fluid, it is possible by means of these newly developed techniques to determine accurately at what stage mouse oocytes can be penetrated. This paper deals with the fertilizability of mouse ovarian oocytes at various stages during

* Present address: Department of Biology, Aichi University of Education, Kariya-City, Aichi-ken, Japan (444). 
maturation and with the morphological aspects of these oocytes after sperm penetration.

\section{MATERIALS AND METHODS}

\section{Medium}

The medium used for the recovery of eggs, incubation of spermatozoa and for fertilization in vitro was very much the same as that used by Cross \& Brinster (1970) and Toyoda, Yokoyama \& Hoshi (1971), which is essentially a modified Krebs-Ringer solution with energy substrates and serum albumin used by Whitten (1957). It should be emphasized here that good crystalline bovine serum albumin kept in the refrigerator should be used for the induction of sperm capacitation.

\section{Collection of oocytes at various stages during maturation}

Mature female Swiss albino mice, weighing between 20 and $24 \mathrm{~g}$, kept in an air-conditioned room at 21 to $23^{\circ} \mathrm{C}$ under controlled light/dark conditions ( 06.00 to 18.00 hours light) were injected intraperitoneally with 5 to 10 i.u. PMSG (Equinex, Ayerst Lab.) in $0.2 \mathrm{ml}$ saline to increase the number of follicles, and $48 \mathrm{hr}$ later with 5 to $10 \mathrm{i}$.u. HGG (APL, Ayerst Lab.) in $0.2 \mathrm{ml}$ saline for the induction of ovulation. The females were killed at various times after the injection of HCG for the collection of ovarian oocytes. After removal, the ovaries were cleared of any adhering blood and placed in a watch glass under oil. Under a dissecting microscope, the large follicles were broken by means of sharp glass needles. The oocytes in the cumulus clot were suspended in the medium containing $0.1 \%$ hyaluronidase for about $5 \mathrm{~min}$ in order to disperse the follicular cells. The oocytes were washed twice in the same medium without hyaluronidase and then transferred to another watch glass containing $0.5 \mathrm{ml}$ medium covered with oil. Twenty to thirty oocytes were then transferred to about $0.02 \mathrm{ml}$ medium covered with oil in a tissue culture dish $(60 \times 15 \mathrm{~mm}$, Falcon plastic tissue culture dish) which was kept in an incubator at $37^{\circ} \mathrm{C}$ saturated with $5 \% \mathrm{CO}_{2}$ in air.

\section{Incubation of spermatozoa for the induction of capacitation}

The cauda epididymidis was removed from both right and left sides of a mature fertile Swiss mouse and placed in a watch-glass containing $1 \mathrm{ml}$ medium at 30 to $37^{\circ} \mathrm{C}$. By cutting the epididymides several times, a mass of active spermatozoa was liberated into the medium. The sperm suspension was then diluted with the medium to a concentration of 3 to $11 \times 10^{3}$ spermatozoa $/ \mathrm{mm}^{3}$. About $1 \mathrm{ml}$ of the sperm suspension under oil was incubated for 2 to $4 \mathrm{hr}$.

\section{Insemination}

About $0.1 \mathrm{ml}$ of the preincubated sperm suspension was thoroughly mixed with the droplet containing oocytes. The time of insemination was arranged precisely 20 to $30 \mathrm{~min}$ after the recovery of the oocytes. All the instruments, syringes, pipettes and watch glasses were sterilized and aseptic precautions were strictly observed during the manipulation of spermatozoa and eggs. 


\section{Examination of eggs}

For the determination of maturation of oocytes in culture and their subsequent penetration, the oocytes were examined 4 to $5 \mathrm{hr}$ after insemination. To determine whether sperm penetration occurred in a definite period, oocytes were washed twice 1 to $2 \mathrm{hr}$ after insemination and transferred into another dish for further incubation of 10 to $18 \mathrm{hr}$, after which they were examined to ascertain the transformation of the sperm head, and the maturation stages of the oocytes.

At various times after insemination, or after further incubation, the oocytes were picked up and treated with $0.1 \%$ hyaluronidase in saline in order to disperse the follicular cells. The oocytes were then washed and placed in the centre of four vaseline spots on a glass slide and anchored carefully in between a coverslip and the slide. They were first examined before fixation under a phase-contrast microscope, then fixed in $10 \%$ neutral formalin overnight and stained with $0.5 \%$ Lacmoid in $45 \%$ acetic acid for morphological study in detail.

Throughout this study, a 'penetrated oocyte' denotes an oocyte that has been penetrated by spermatozoa. The spermatozoon may be an intact one in the perivitelline space, or may have entered the vitellus. An 'oocyte undergoing fertilization' denotes one in which the spermatozoon has entered the vitellus, and further changes have occurred to the head from enlargement to the formation of a male pronucleus.

\section{RESULTS}

\section{Sperm penetration and maturation of oocytes following insemination}

Before the experiment, about fifty oocytes had been examined at various times after injection of HCG and the proportion of oocytes at various stages had been estimated. The highest proportions of oocytes at a particular time after injection of HCG without incubation are presented in the first column of Table 1. The stages of maturation, as shown in Table 1, before and after incubation for 4 to $5 \mathrm{hr}$ were arbitrarily classified, with reference to the photographs of Donahue (1968).

When oocytes collected without the injection of HCG or $8 \mathrm{hr}$ after injection of HCG were inseminated in vitro and incubated for 4 to $5 \mathrm{hr}$, their nuclear maturation advanced to a similar stage as in vivo (Table 1). Their nuclear changes during in vitro incubation with spermatozoa were almost the same as in vivo after injection of HCG. However, an appreciable delay in the process of maturation during incubation was shown in the oocytes inseminated $10 \mathrm{hr}$ after the injection of HGG. The proportion of penetrated eggs appeared to be lower when the oocytes were inseminated 0 to $4 \mathrm{hr}$ after injection of HCG (12 to $35 \%$ ) than when inseminated 6 to $10 \mathrm{hr}$ after injection ( 53 to $69 \%$ ). This indicates that the fertilizability of oocytes at later stages is better than at earlier stages, although the latter can be penetrated.

\section{Sperm penetration at various stages during maturation}

In order to determine more accurately at what stage during maturation 
ooctyes can be penetrated by spermatozoa, the oocytes were collected according to their stages of maturation at various times after injection of HGG and inseminated. They were examined 1, 2, 3, 4 or $5 \mathrm{hr}$ after insemination. From the results presented in Table 2, it can be seen that the proportion of penetrated oocytes gradually increased as the maturation of oocytes advanced, that the proportion of penetrated oocytes within $1 \mathrm{hr}$ of insemination was higher (29 to $75 \%$ ) after Metaphase I than before Metaphase I (2 to $15 \%$ ), and that sperm penetration almost ceased $4 \mathrm{hr}$ after insemination. The majority of oocytes had many spermatozoa in the perivitelline space. The sperm heads could swell in the vitellus within $1 \mathrm{hr}$ of insemination. However, an enlarged sperm head could not be found in the primary oocytes inseminated at the germinal vesicle stage, showing the possibility of penetration through the zona pellucida but failure to become incorporated with the vitellus. A low proportion of oocytes undergoing fertilization ( 0 to $67 \%$ ) was observed when insemination took place before Metaphase I, but a high proportion (25 to 100\%) was found when insemination took place after Metaphase I. This shows that the acceptance of spermatozoa improved as the oocytes became more mature.

\section{Changes of sperm nucleus incorporated with oocytes at various stages of maturation}

In order to determine the exact time of sperm penetration and the morphological changes occurring in the sperm head in the vitellus without further entry of spermatozoa, oocytes collected 6 to $10 \mathrm{hr}$ after the injection of HGG were incubated with spermatozoa for only 1 to $2 \mathrm{hr}$. The oocytes were then washed twice and further incubated for 10 to $18 \mathrm{hr}$. From the results presented in Table 3, it can be seen that the proportion of penetrated oocytes (58 to $81 \%$ ) and that of oocytes undergoing fertilization ( 50 to $84 \%$ ) were not very different among oocytes inseminated from 6 to $10 \mathrm{hr}$ after injection of HGG. Although the average number of spermatozoa in the vitellus was very much the same, the number of spermatozoa that had penetrated through the zona pellucida was higher (thirteen to seventeen) when oocytes were inseminated 6 to $7 \mathrm{hr}$ after the

\section{EXPLANATION OF PLATE 1}

All the oocytes were photographed after being stained with Lacmoid. Phase-contrast microscopy with $\times 10$ ocular and $\times 40$ objective.

FIG. 1. An oocyte with an enlarged sperm head at the stage of chromatin condensation. This oocyte, recovered $6 \mathrm{hr}$ after injection of HCG, was inseminated and incubated for 5 hr. Approx. $\times 370$.

Frg. 2. The same oocyte as shown in Fig. 1 with enlarged sperm head and the first maturation spindle (MI) which is out of focus. Approx. $\times 1420$.

Fig. 3. An oocyte with the first polar body (pb), a ring-shaped male chromatin (cd), and the second maturation spindle (M2). This oocyte, recovered $10 \mathrm{hr}$ after injection of HCG, was incubated with spermatozoa for $2 \mathrm{hr}$. After washing, it was incubated for $16 \mathrm{hr}$. Approx. $\times 370$.

FIG. 4. The same oocyte as in Fig. 3, showing the ring-shaped male chromatin (cd), the maturation spindle (M2), and the sperm tail (arrow). Approx. $\times 1420$.

Fig. 5. An oocyte with a spindle-like male chromatin (cd) and the second maturation spindle (M2). This oocyte, recovered $8 \mathrm{hr}$ after injection of HCG, was incubated with spermatozoa for $2 \mathrm{hr}$. Approx. $\times 370$.

FIG. 6. The same oocyte as in Fig. 5, showing the sperm tail (arrow) and the spindle-like male chromatin (cd). Approx. $\times 1420$. 


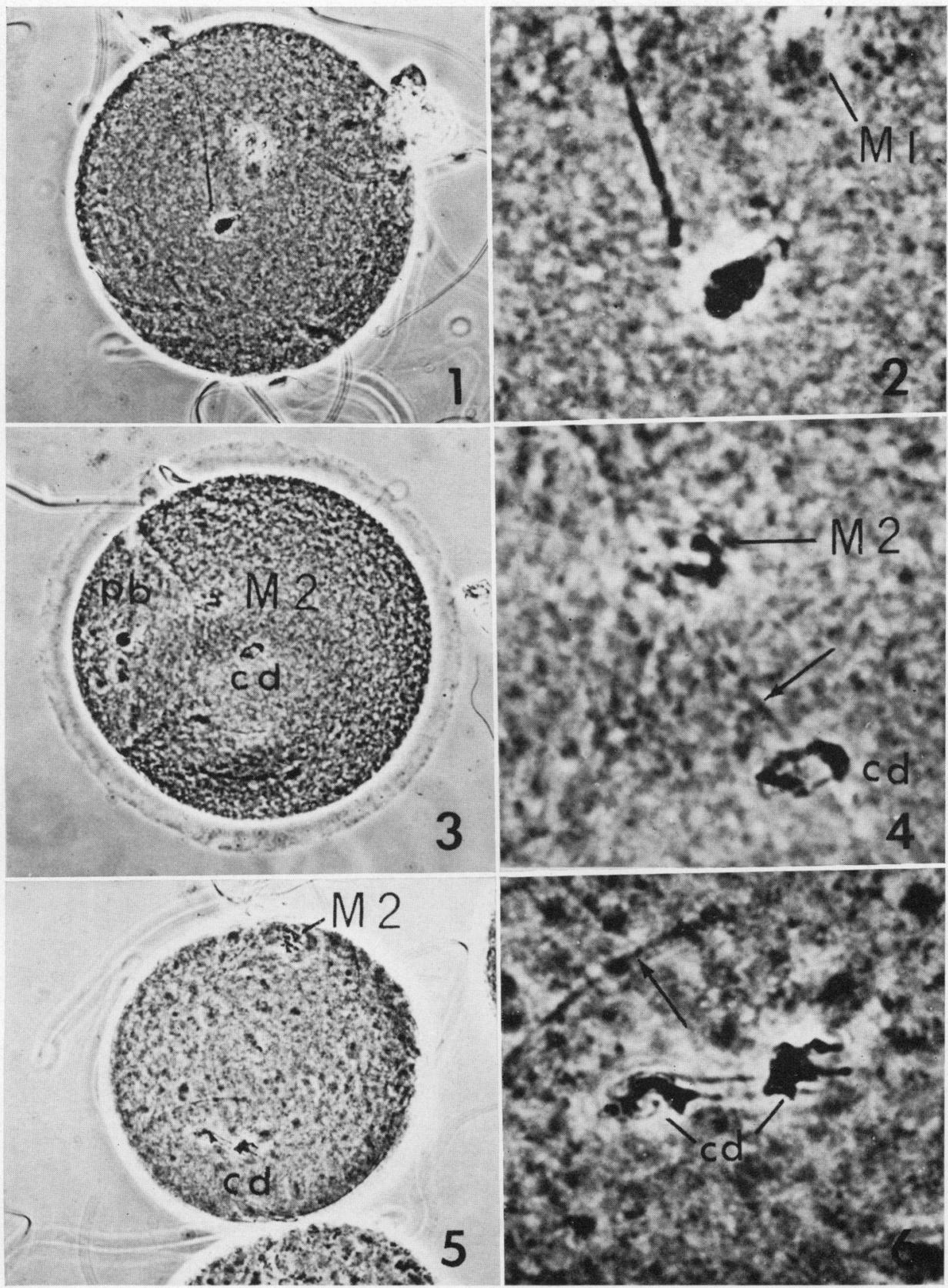


14ting cotily $-2.1 .01=$ a $x$ und cot Fention 5 sustom 47
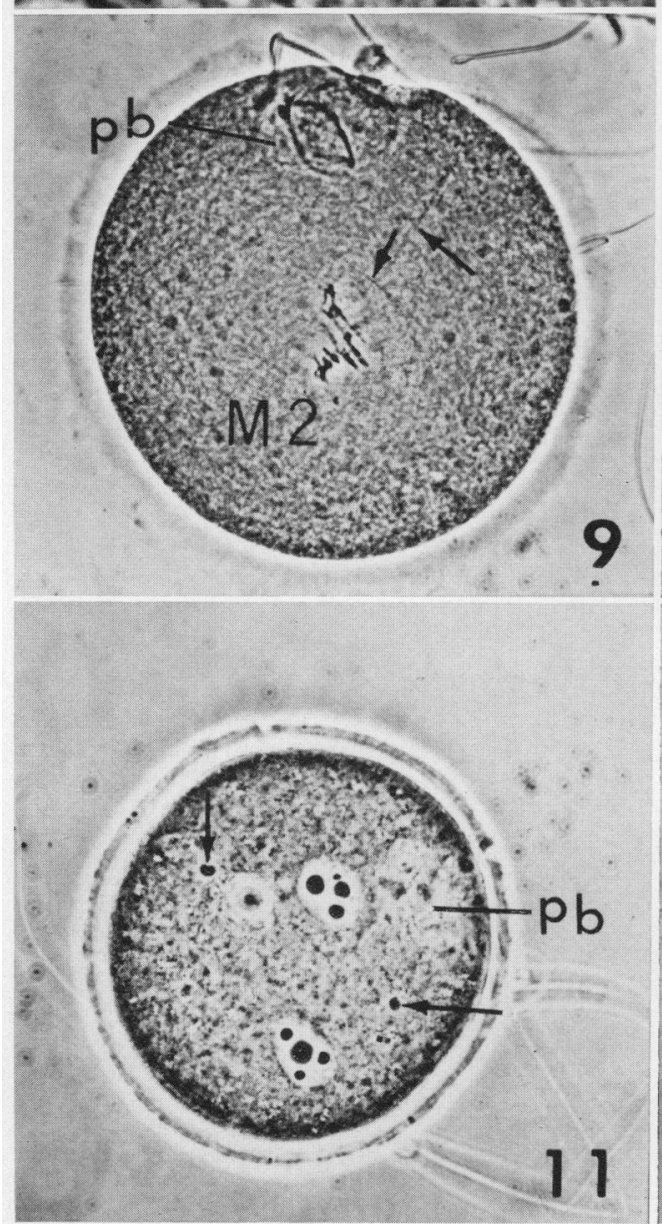

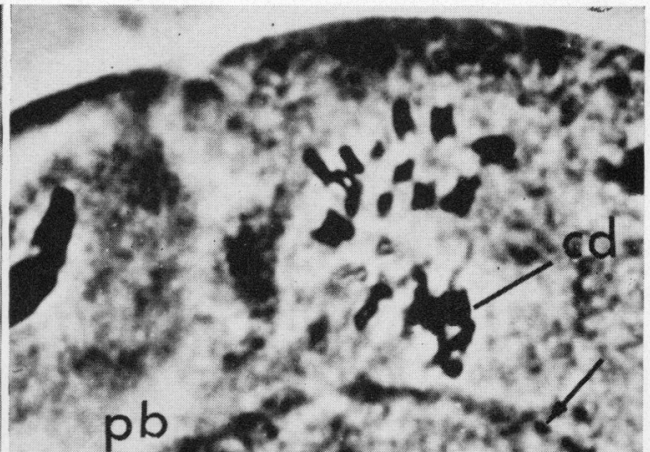

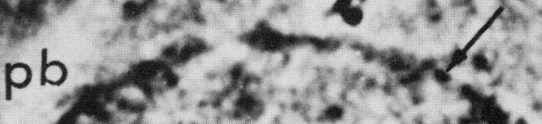

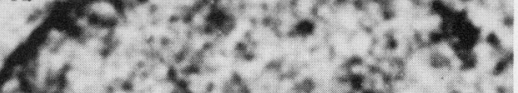

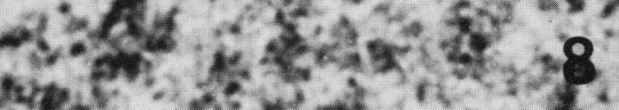

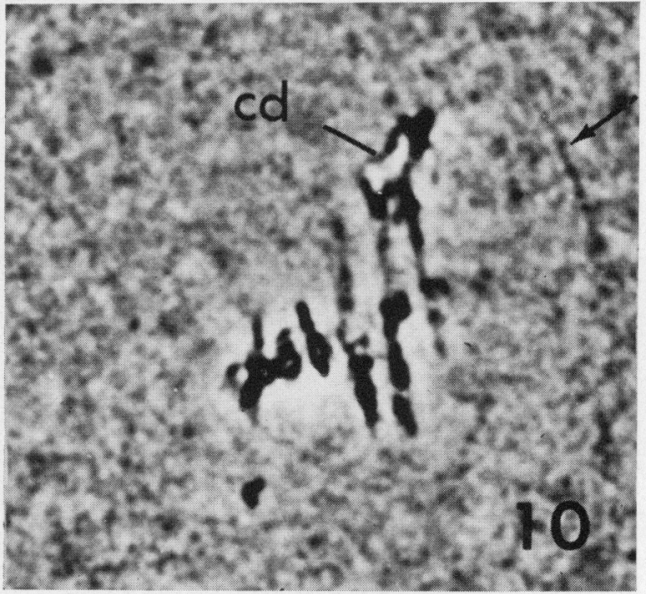

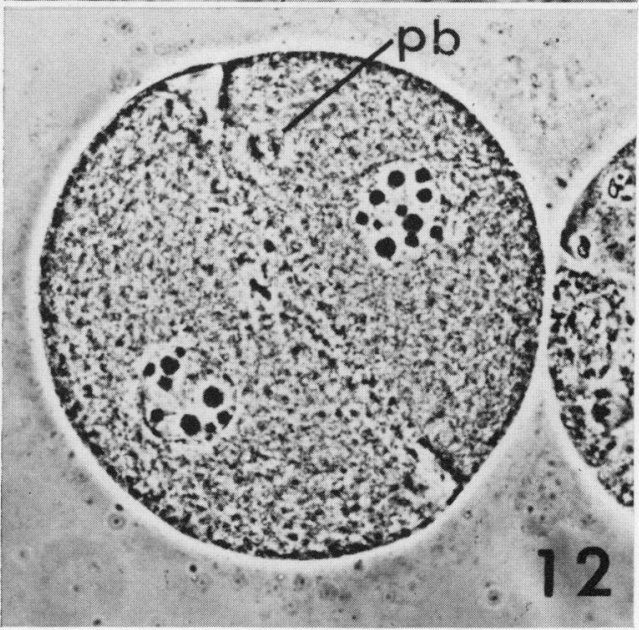


injection of HGG than 8 to $10 \mathrm{hr}$ after injection of HCG (two to six). This indicates that the mechanism to block sperm entry by the zona pellucida was weak during the early stages of oocyte maturation.

Most oocytes undergoing fertilization before Metaphase I had a condensed mass of chromatin from the sperm head (Pl. 1, Figs 1 and 2). The sperm head was swollen but did not transform into a pronucleus and shrank within $1 \mathrm{hr}$. The time required to form a sperm chromatin mass in the oocytes at the condensed germinal vesicle stage was not different from those oocytes inseminated at Metaphase I and, morphologically, the male chromatin was very similar in the cytoplasm of oocytes before Metaphase I. As shown in Table 3, when inseminated oocytes 6 to $9 \mathrm{hr}$ after injection of HGG were incubated further for 10 to $18 \mathrm{hr}$, two normal pronuclei, one female and one male with corresponding sperm tail, were formed in a small number ( 7 to $20 \%$ ) of oocytes undergoing fertilization. Frequently, in these oocytes with normal pronuclei, 'immediate cleavage' was observed (Table 3 ). The number of oocytes with two normal pronuclei and one sperm tail in the cytoplasm was approximately the same as that of spontaneously activated oocytes with one pronucleus without a sperm tail (Table 3). Ten hours after injection of HGG, however, the proportion of oocytes with two pronuclei increased $(55 \%$ versus 7 to $20 \%$, whereas that of oocytes with condensed male chromatin decreased slightly $(37 \%$ versus 63 to $86 \%$ ). Of eighty-two penetrated oocytes $10 \mathrm{hr}$ after injection of HGG (at Metaphase I-Telophase I), $55 \%$ had normal male and female pronuclei at the end of a further incubation for 10 to $18 \mathrm{hr}$ (Table 3). The proportion of oocytes undergoing fertilization became higher $(55$ to $84 \%$ ) in the oocytes $10 \mathrm{hr}$ after injection of HCG than those ( 46 to $67 \%$ ) 6 to $9 \mathrm{hr}$ after injection of HGG (Tables 1 and 3). These observations may indicate that cytoplasmic maturation occurred at Metaphase I-Telophase I, $10 \mathrm{hr}$ after injection of HCG.

In about 17 to $30 \%$ of oocytes which had a condensed male chromatin

\section{EXPLANATION OF PLATE 2}

All the oocytes were photographed after being stained with Lacmoid. Phase-contrast microscopy with $\times 10$ ocular and $\times 40$ objective.

Fic. 7. The first maturation spindle with condensed male chromatin (cd). This oocyte, recovered $6 \mathrm{hr}$ after injection of HCG, was incubated with spermatozoa for $3 \mathrm{hr}$. Approx. $\times 1420$.

FIG. 8. The second maturation spindle with condensed male chromatin (cd), showing sperm tail (arrow) and the first polar body $(\mathrm{pb})$. This oocyte, recovered $8 \mathrm{hr}$ after injection of HCG, was incubated with spermatozoa for $2 \mathrm{hr}$. After washing, it was incubated for $17 \mathrm{hr}$. Approx. $\times 1420$.

FIG. 9. An oocyte with the second maturation spindle (M2) with condensed male chromatin, showing also the first polar body ( $\mathrm{pb}$ ) and two sperm tails (arrows). This oocyte, recovered $10 \mathrm{hr}$ after injection of HCG, was incubated with spermatozoa for $2 \mathrm{hr}$. After washing, it was incubated for $16 \mathrm{hr}$. Approx. $\times 370$.

Fig. 10. The second maturation spindle of the same oocyte as shown in Fig. 9, showing the possible condensed male chromatin (cd) and a sperm tail (arrow). Approx. $\times 1420$. Fig. 11. An oocyte with the first polar body (pb), three pronuclei and two condensed male chromatin (arrows). This oocyte, recovered $6 \mathrm{hr}$ after injection of HCG, was reinseminated $5 \mathrm{hr}$ after the first insemination and then incubated for $15 \mathrm{hr}$. Approx. $\times 370$.

Frg. 12. A cleaved oocyte inseminated $6 \mathrm{hr}$ after injection of HCG, reinseminated $5 \mathrm{hr}$ later and then incubated for $18 \mathrm{hr}$. Approx. $\times 370$. 


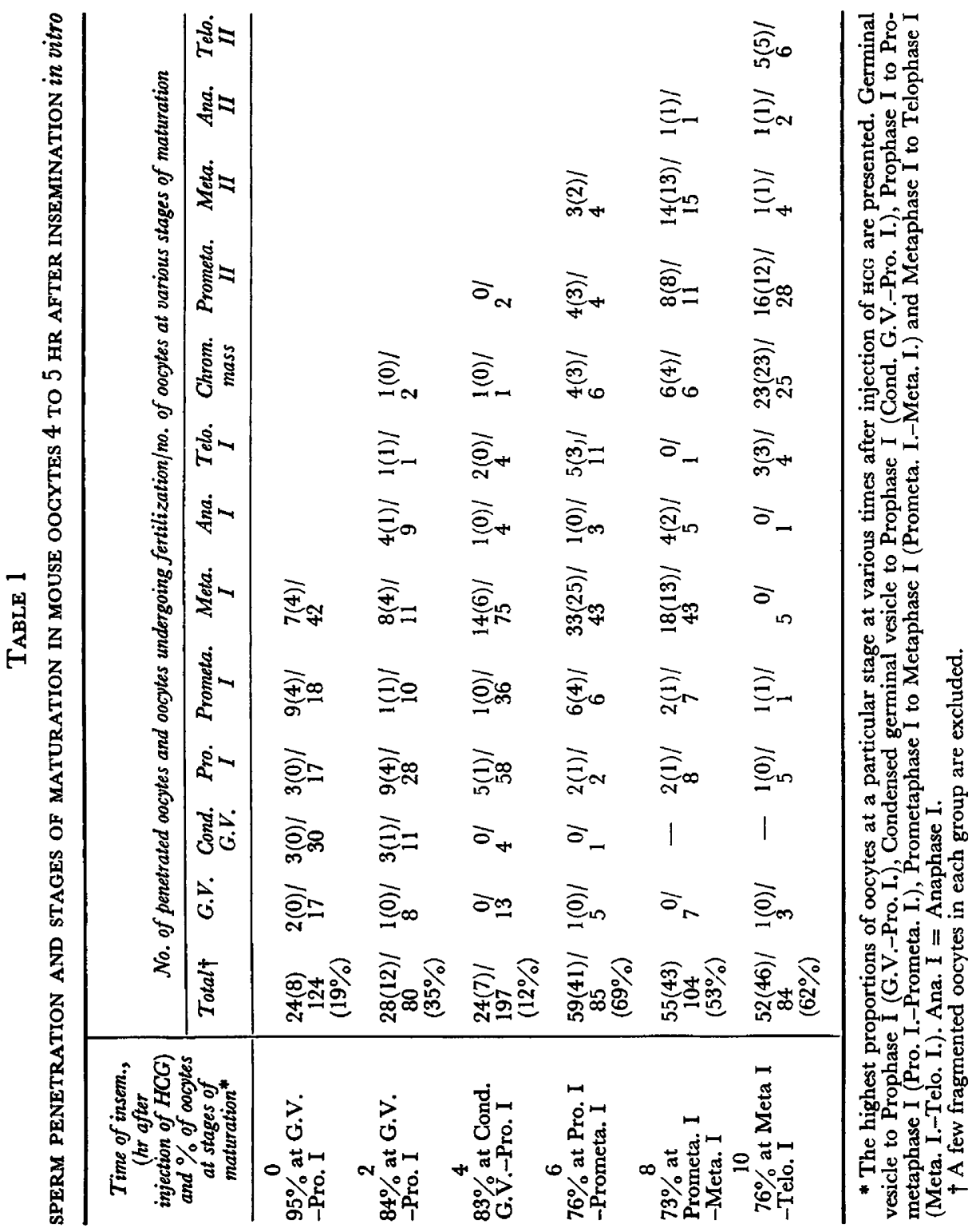




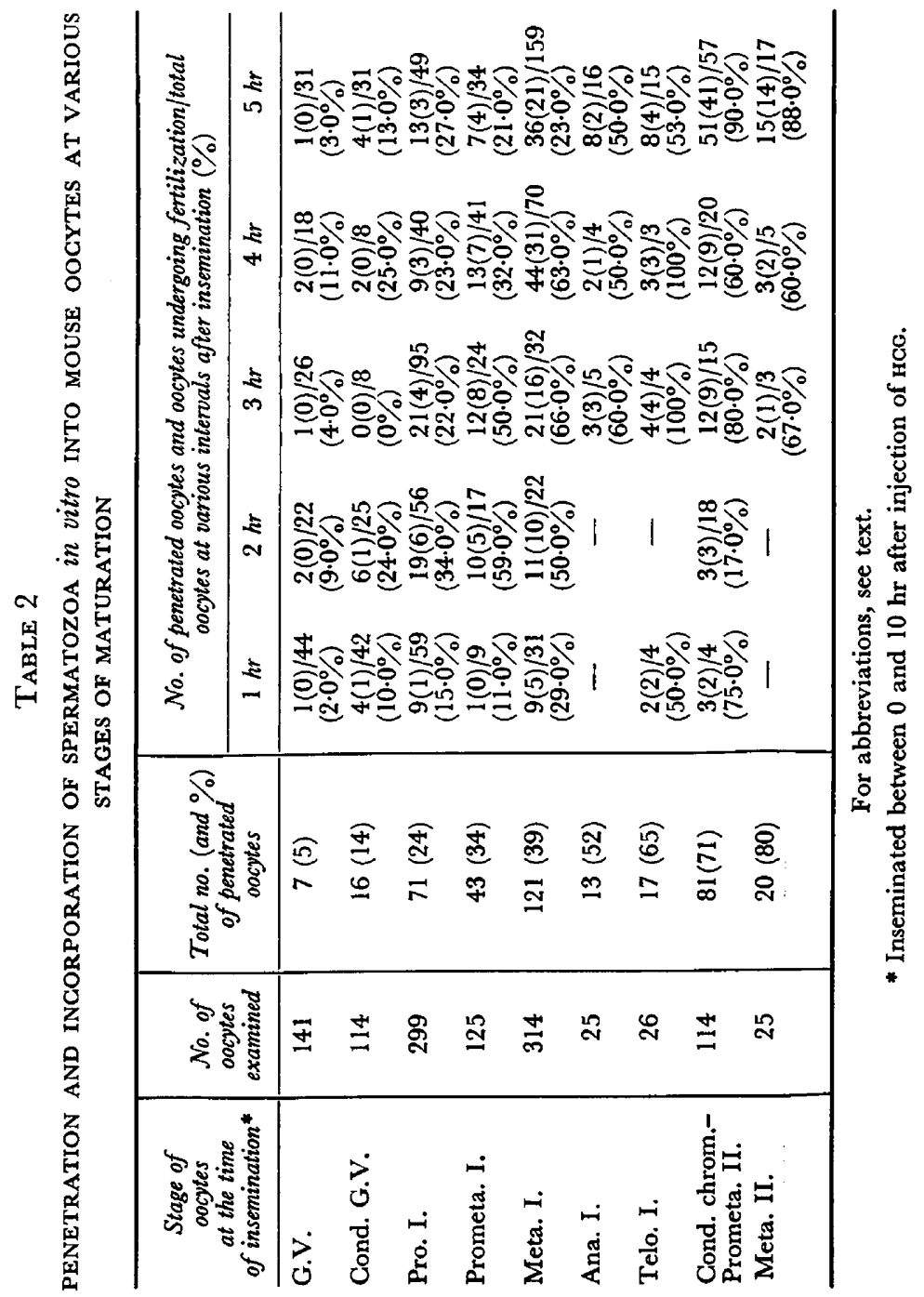




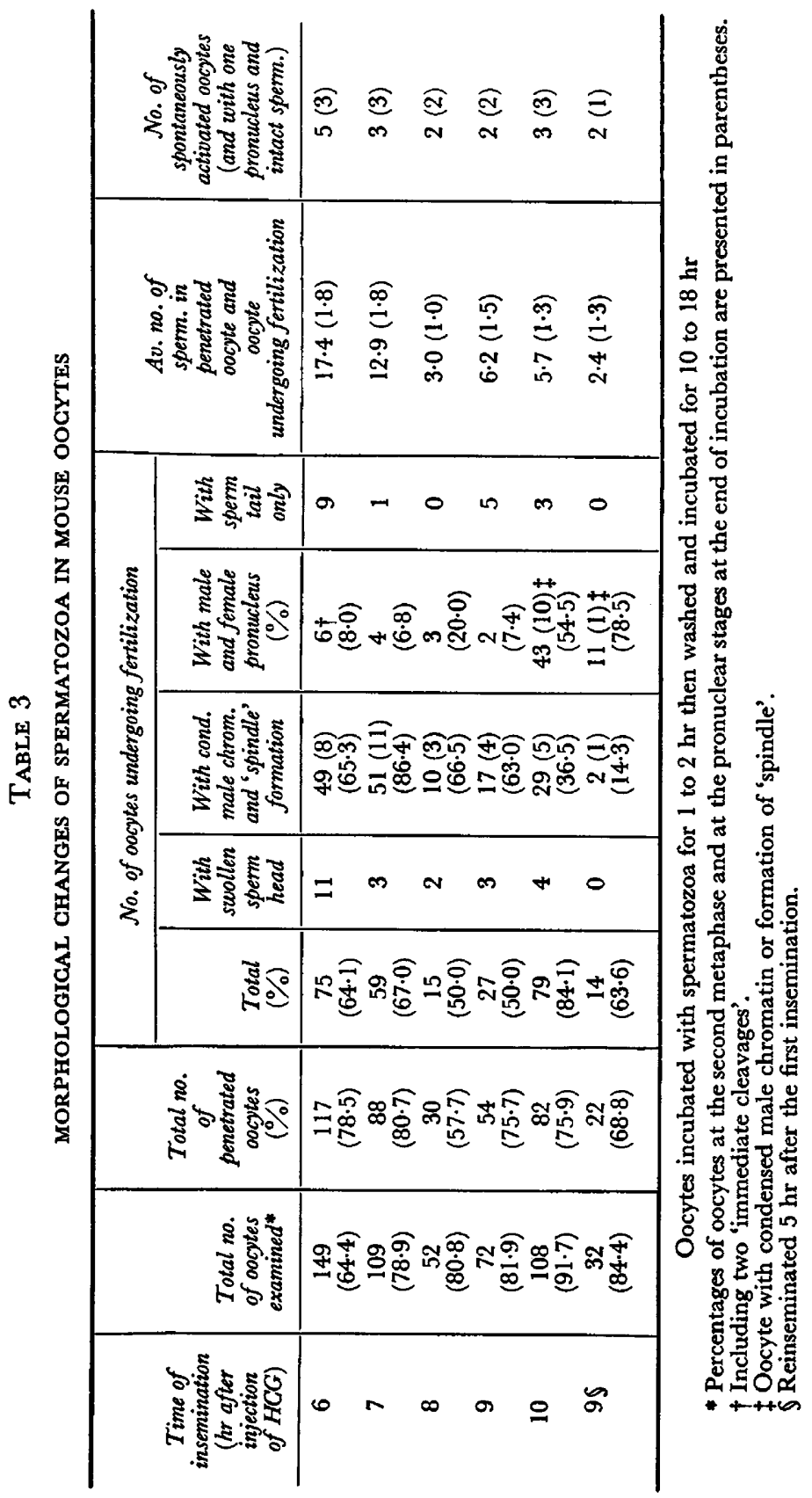


mass, the mass appeared to transform to a 'spindle' (Pl. 1, Figs 3 to 6), although in the majority of oocytes such chromatin masses did not undergo such change. It seems that the transformation of male chromatin stopped at this stage without further activity at the end of incubation for 10 to $18 \mathrm{hr}$. In some cases, both female chromatin and male chromatin formed a mass, probably as a result of being close together (P1. 2, Figs 7 to 10). Such formation with a single spindle definitely consisted of male chromatin because of the presence of a sperm tail in the cytoplasm.

Sixty-six oocytes inseminated $6 \mathrm{hr}$ after the injection of HCG were washed 1 to $2 \mathrm{hr}$ after insemination and reinseminated $5 \mathrm{hr}$ later. Seven cleaved oocytes $(11 \%)$ were observed $18 \mathrm{hr}$ after reinsemination. When the oocytes previously inseminated $9 \mathrm{hr}$ after injection of HCG were washed and reinseminated $5 \mathrm{hr}$ later, $79 \%$ had one to three morphologically normal nuclei in the presence of the second polar body. The proportion of such pronuclear oocytes was higher $(79 \%)$ than when oocytes were inseminated only once (7 to $55 \%)$.

\section{DISGUSSION}

When ovarian oocytes recovered $9 \mathrm{hr}$ after injection of HCG were incubated with fresh epididymal spermatozoa for $8 \mathrm{hr}, 82 \%$ were penetrated and $68 \%$ were undergoing fertilization (Iwamatsu \& Chang, 1971). As revealed in the present study, although sperm penetration was possible without, or $6 \mathrm{hr}$ after, injection of HCG $(12$ to $35 \%$ ), the proportion of penetrated oocytes was relatively higher ( 53 to $69 \%$ ) 6 to $10 \mathrm{hr}$ after the injection of HCG (Table 1). The gradual increase in the proportion of penetrated oocytes was clearer when oocytes in a particular stage were inseminated (Table 2). A clear-cut demarcation, however, could not be established.

It has been stated that the cytoplasmic maturation takes place after the incorporation of the nucleoplasm (germinal vesicle material) with the cytoplasm (cf. Monroy \& Tyler, 1967). It seems that the germinal vesicle material is essential to induce cytoplasmic maturation (the acquisition of capacities for cleavage and replication of DNA) of the oocyte, especially for the induction of DNA synthesis in amphibian oocytes (Gurdon, 1967; Gurdon \& Speight, 1969). In most animals, acquisition of both capacities for cleavage and DNA synthesis seems to appear at the same time after the breakdown of the germinal vesicle. By contrast, it has been shown that in Holothuria (Rawitz, 1901) and fish (Iwamatsu, 1966) developmental capacity appears independently of the breakdown of the germinal vesicle. In the present study on mouse oocytes, the formation of a male pronucleus was not observed in the oocytes at the germinal vesicle stage after sperm penetration in vitro. A similar observation in vivo in the rat primary oocyte has been mentioned (cf. Austin, 1961). This may suggest that in mammalian oocytes cytoplasm without the incorporation of germinal vesicle material has no capacity to transform the sperm head into a male pronucleus. Furthermore, as seen in the present study, mouse oocytes during the maturation from the germinal vesicle stage to Metaphase I ( 0 to $8 \mathrm{hr}$ after injection of $\mathrm{HCG}$ ) could be penetrated by spermatozoa and their nuclear 
maturation could proceed to Metaphase II. However, 9 to $10 \mathrm{hr}$ after the injection of $\mathrm{HCG}$, their potential fertilizability increased.

It was also found in the present study that potential reception of spermatozoa by mouse oocytes increased gradually from the condensed germinal vesicle stage to Telophase I (from 4 to $10 \mathrm{hr}$ after the injection of HCG), the enlargement of sperm heads becoming more rapid as in mature eggs. Ten hours after injection of HCG, the cytoplasm of mouse oocytes was more efficient for the transformation of the male and female pronuclei.

With regard to the acquisition of capacity for cleavage, 'immediate cleavage' was observed when oocytes were inseminated $6 \mathrm{hr}$ after injection of HCG and then incubated further for $10 \mathrm{hr}$, at the completion of the first or the second maturation division. The occurrence of this type of cleavage at the Metaphase II of mature mouse eggs has been reported by Braden \& Austin (1954) and Marston \& Chang (1964). In the present study, such cleavage at the Metaphase II was not observed within $10 \mathrm{hr}$ after injection of HCG at the stage of Metaphase I-Telophase I.

In the dog, sperm penetration generally takes place during the first maturation division (Van der Stricht, 1923). According to Noyes (1952), fertilization in vivo and development were possible when rat ovarian oocytes were at the first meiotic division. It was also reported by Chang (1955) that, in the rabbit, fertilization in vivo and development were possible only if the oocytes were at the stage of the first maturation division. These and the present observations on mouse oocytes suggest that fertilizability of mammalian oocytes is acquired just before or at the completion of the first maturation division. Thus, the acquisition of fertilizability occurs at similar time intervals after the breakdown of the germinal vesicle, even though the time of ovulation and fertilization is different among different species.

The nuclear maturation of oocytes in culture has been reported in many mammalian species by many workers (cf. Edwards, 1965). It has been reported that $92 \%$ of mouse oocytes at the germinal vesicle stage could mature in culture but only $38 \%$ of these oocytes could be fertilized in vitro and only $3 \%$ of them could develop into fetuses when transferred to recipients (Cross \& Brinster, 1970). The fertilizability of oocytes, as revealed in the present study, depends not only on the nuclear maturation but also on the maturation of the cytoplasm. This again supports the notion that 'although the nuclear maturation is a good indication of the maturity of the ova, the maturation of ooplasm as a whole should be considered as an important factor for fertilization' (Chang, 1955).

\section{ACKNOWLEDGMENT}

This work was supported by a grant (GM 14370) from the National Institute of Health and a grant from the Ford Foundation. M.C.C. was a Research Career Awardee of the NICHD (K6-HD 18, 334).

\section{REFERENCES}

Austin, C. R. (1961) The mammalian egg. Blackwell Scientific Publications, Oxford.

Braden, A. W. H. \& Austin, C. R. (1954) Reactions of unfertilized mouse eggs to some experimental stimuli. Expl Cell Res. 7, 277. 
CHANG, M. C. (1955) The maturation of rabbit oocytes in culture and their maturation, activation, fertilization and subsequent development in the Fallopian tubes. F. exp. Zool. 128, 379.

Cross, P. C. \& Brinster, R. L. (1970) In vitro development of mouse oocytes. Biol. Reprod. 3, 298.

Donahus, R. P. (1968) Maturation of the mouse oocyte in vitro. I. Sequence and timing of nuclear progression. J. exp. Zool. 169, 237.

EDWARDS, R. G. (1965) Maturation in vitro of mouse, sheep, cow, pig, rhesus monkey and human ovarian oocytes. Nature, Lond. 208, 349.

GuRdon, J. B. (1967) On the origin and persistence of a cytoplasmic state including nuclear DNA synthesis in frog's eggs. Proc. natn. Acad. Sci. U.S.A. 58, 545.

Gurdon, J. B. \& Speight, V. A. (1969) The appearance of cytoplasmic and polymerase activity during the maturation of amphibian oocytes in to eggs. Expl Cell Res. 55, 253.

Iwamatsu, T. (1966) Role of germinal vesicle materials on the acquisition of developmental capacity of the fish oocyte. Embryologia, 6, 205.

Iwamatsu, T. \& Chang, M. C. (1969) In vitro fertilization of mouse eggs in the presence of bovine follicular fluid. Nature, Lond. 224, 919.

Iwamatsu, T. \& Chang, M. G. (1970) Further investigation of capacitation of sperm and fertilization of mouse eggs in vitro. $\mathcal{F}$. exp. Zool. 175, 271.

Inamatsu, T. \& Chang, M. C. (1971) Factors involved in the fertilization of mouse eggs in vitro. $\mathcal{J}$. Reprod. Fert. 26, 197.

Marston, J. H. \& Ghang, M. G. (1964) The fertilizable life of ova and their morphology following delayed insemination in mature and immature mice. F. exp. Zool. 155, 237.

Monroy, A. \& TYLER, A. (1967) The activation of the eggs. In: Fertilization, p. 696. Eds. C. B. Metz and A. Monroy. Academic Press, New York.

Muknerjee, A. B. \& Cohen, M. M. (1970) Development of normal mice by in vitro fertilization. Nature, Lond. 228, 472.

Noyes, R. W. (1952) Fertilization of follicular ova. Fert. Steril. 3, 1.

RawrTz, B. (1901) Versuche über Ephebogenesis. Roux Arch. Entw.-Mech. 11, 207.

'Toyoda, Y. Yokoyama, M. \& Hoshi, T. (1971) Studies on the fertilization of mouse eggs in vitro. I. In vitro fertilization of eggs by fresh epididymal sperm. Jap. F. Anim. Reprod. 16, 1.

VAN DER Strichr (1923) Etude comparée des ovules des mammifères aux différentes périodes de l'ovogénèse, d'aprés les travaux du Laboratoire d'Histologie et d'Embryologie de l'Université de Gand. Archs Biol., Paris, 33, 229.

Whitten, W. K. (1957) Culture of tubal ova. Nature, Lond. 179, 1081.

Whittingham, D. G. (1968) Fertilization of mouse eggs in vitro. Nature, Lond. 220, 592.

YANAGIMAGHI, R. (1969) In vitro acrosome reaction and capacitation of hamster spermatozoa by bovine follicular fluid and its fractions. F. exp. Zool. 170, 269. 